\title{
SERIOUS CRIME IN NIGERIA: AN EMPIRICAL ANALYSIS USING TIME SERIES DATA(BETWEEN 2000-2010)
}

DAVID F. ADIELE

\begin{abstract}
This paper empirically examined the effect of the clearance rate, the unemployment rate, the percentage of females in employment and the percentage of the labour force with tertiary education on Serious Crime in Nigeria for the period 2000-2011. Time-series data from (NBS) National Bureau of statistics and Nigeria police annual reports 2011 are used and tests for the existence of a long runcointegration relationship among serious crime, clearance rate and various socio economic indicators is carried out. The cointegration analysis provides strong evidence of the existence of a long-run model. With the normalized coefficients showing a negative effect of the clearance rate, percentage of females in the labourforce and the percentage of the labour force with tertiary education on serious crime, with the exception being the unemployment rate which is found to exert a positive effect.
\end{abstract}

\section{KEYWORDS:Crime, Cointegration, Unit Root, Time-Series.}

\section{INTRODUCTION}

Research on the causes of crime has received an enormous amount of attention by sociologists and criminologists (see Merton, 1938; Shaw andMekay, 1942: Sutherland, 1942. However, Beeker (1968) suggested that an individual's decision to participate in crime and delinquency could be analyzed through the use of utility theory. The basic assumption of this theory is that an individual is a rational utility maximiser who decides whether or not to engage in criminal activity by comparing the costs and benefits of crime. The seminal work from Beeker has been subsequently extended by Herlich (1973), who considered a time allocation model (i.e individuals have to decide how to allocate their time between legitimate and illegitimate activities) and who was the first to empirically test the economic model of crime. Since the Beeker-Enlrich Model, significant theoretical and empirical developments have been made (see, for example, Grogger, (1995); Witte (1980) and the incentive-based economic model of crime has been increasingly applied to both property and violent crime analysis.

The primary aim of this paper is to examine the effect of two central variables on the incentive-based economic model of crime on serious crime. The two central variables being considered are the clearance rate, which is used as a measure of the ability of the police to solve crimes (or as a general indicator of police performance), and the unemployment rate, which reflects the opportunity for participation in the legitimate job market and the acquisition of legal earnings (see Freeman, 1999). As far as we are aware this is the first study examining aggregated crime data for this country in the West African region.

The rate of increase of crime in Nigeria makes this work expedient. Also, in this study we consider the percentage of females in employment and the percentage of the labour force with tertiary education variables that to date have not received a great deal of attention in crime studies.

\section{Classes of serious crime}

Class I-These are serious offences against the person, including murder, conspiracy to murder, manslaughter, infanticide, attempted murder, suicide and attempted suicide, written threat to commit murder, felonious wounding, acts causing or tending to cause danger to life, rape and unlawful carnal knowledge, abduction, defilement and procurement of women; child-stealing; burglary, abortion and concealment of birth, and unnatural offenses.

Class II- Offences against with violence, includes blackmail and extortion, breaking and breakings with intent and burglaries, possession of house breaking implements and robberies.

Class III- Offences against property (over $\mathbf{N}_{2,000}$ ) without violence. These include embezzlement, falsification of accounts, false pretences, fraud and fraud and fraudulent conversion, general larceny, larceny of motor vehicles, larceny of postal packets, post office felonies, larceny dwelling house/entering dwelling house by night with intent.

Class IV- Malicious injuries to property with intent. These include arson, other malicious damage over $\mathbb{N} 1,000$ (not private dispute) and cattle maiming.

Class V- These crimes take the form of and crimes against currency and include forgery (other than currency note), coinage offences, forgery of currency notes and offences under the Central Bank act and Exchange Control act.

Class VI- These are other serious offences and include treason, sedition, perjury, riot, criminal libel, personation, corruption and firearm offences. trafficking.

Class VII-Narcotice offences- these include trafficking and procession of dangerous drugs for the purpose of 


\section{The Model}

The serious crime rate equation can be written as:

$s c r=f(d e t$, ur.flf.ed $)(1)$

The assumption of linearity in the functional form for $f$ is adopted. We use a log linear specification to measure elasticities. Thus, equation (1) demonstrates a log-linear specification of the model of serious crime:

$l s c r_{t}=\alpha_{1}+\alpha_{2} l d e t_{\mathrm{t}}+\alpha_{3} l u r_{\mathrm{t}} l+\alpha_{4} l f l f_{t}+\alpha_{5} l e d_{\mathrm{t}}+\varepsilon_{\mathrm{t}}$

wheret represents time period and /denotes natural logarithms.

The expected signs of the coefficients $\alpha_{\mathrm{i}}\left(i=2\right.$ and 3 ) in equation (2) are: (i) $\alpha_{2}<0$ : the economic model predicts that an increase in the probability of being caught (and punished) decreases the expected utility of crime; and (ii) $\alpha_{3}>0$ : the exclusion from legal income opportunities increase the returns to crime. There are some significant empirical studies on violent crime, however, that underline that the basic assumptions of the economic model regarding the deterrence effect and the relationship between unemployment and crime, may be more important factors for property crime than violent crime (e.gSaridakis, 2008; 2004; Raphael and Winter-Ebmer, 2001: Cherry and list, 2002; Entorf and Spengler, 2000). Finally, for the coefficients $\alpha_{i}\left(\mathrm{i}=4\right.$ and 5) we expect: (iii) $\alpha_{4}>0$ : the increased entry of women into employment increase the overall supply of workers thus lowering wages, which may in turn increase crime and (iv) $\alpha_{5}$ $<0$ : education increases the returns to legitimate work and raises the opportunity cost of engaging in criminal activity (see Lochner, 2004).Recall, the shop coefficient in a log linear specification shows the percentage change in the dependent variable per unit off a percentage change in an independent variable.

\section{Data}

The data used in this study was obtained from the National Bureau of Statistics (NBS) yearly publication and from Nigeria Police Force Annual report. Serious crimes are all indictable offences carrying a penalty of five or more years, for which prosecutions have been instituted in the High Court. Although this goes beyond the scope of this paper, we acknowledge that police crime statistics are based on cases that are reported to the police by the public and thus, there might be significant under-reporting of offences (especially violence against women and children).

TABLE 1:Summarize LSC LCR LUR LEF LLF

\begin{tabular}{rrrrrr} 
Variable & Obs & Mean & Std. Dev. & Min & Max \\
\hline LSC & 31 & 11.89912 & .6107626 & 9.6676524 & 12.94652 \\
LCR & 31 & 3.88933 & .4186611 & 2.80336 & 4.347694 \\
LUR & 31 & 2.431929 & .2335985 & 1.960095 & 3.063391 \\
LEF & 31 & 3.901799 & .2015177 & 3.33577 & 4.222445 \\
LLF & 31 & 4.501738 & 0.44269 & 4.370713 & 4.564348
\end{tabular}

\section{Statistics Framework}

In order to determine the size of the coefficients in equation (2) we could estimate it using Ordinary Least square (OLS). Since many of the variables are dominated by strong time trends as well as possible endogeneity between serious crime and clearance rate (i.e the level of crime determines the workload of the police and thus, the success of solving offences) application of OLS might produce biased estimates of the coefficients. Following previous work (see Saridakis, 2008. 2004: Witt and Witte, 2001; Freeman, 1999; Pyle and Deahman. 1994: Hale and Sabbagh, 1991) we use a cointegrating Vector Autoregressive (VAR) model to resolve these problems.

Specifically, we have used a generalized version of Johansen's $(1998,1995)$ maximum likehood approach described by Pesaran (1997) and estimated an unrestricted VAR model for serious crime in Nigeria as follows:

$$
\begin{gathered}
p-1 \\
\Delta \mathrm{y}_{\mathrm{t}}=\alpha_{0 y}+\alpha_{i v} \Pi_{\mathrm{y}} z t_{-1}+\sum_{t=1}^{\Gamma 1 y} \quad \Delta \mathrm{z} t_{-1}+v_{\mathrm{t}}
\end{gathered}
$$

where $z_{t}=\left(y_{t}{ }^{1}, x_{t}\right)^{1}$ with $y_{t}$ being the vector of jointly determined (endogenous) $l(1)$ variables (serious crime and clearance rates) and $x_{t}$ being the vector of exogenous $\mathrm{I}(1)$ variables (unemployment rate, employed female population and labour force with tertiary education). $\Delta$ is the difference operator. The intercept and the trend coefficients are $\alpha_{0 y}$, and $\alpha_{1 y}$, respectively. $v_{\mathrm{t}}$ is the vector of serially uncorrelated shocks. 
RESULTS

Before estimation of the cointegrated VAR model, we need to ensure a stationary representation of the model. The Augmented Dickey Fuller (ADF) test is one of the most frequently used tests for unit roots. The null hypothesis is that there exists a unit root or that the series is I(1). The results of the ADF test are presented in table 2. It shows that the null of a unit root of the variables at levels cannot be rejected for any of the variables at the $5 \%$ level of significance. However, the series become stationary after first differencing. We use a lag length of 2 in the VAR: we found that there is no evidence of serial correlation in any of the endogenous equations using the LM test for up to second order serial correlation.

TABLE 2:

RESULT OF THE AUGMENTED DICKEY-FULLER TEST FOR UNIT ROOTS

\begin{tabular}{r|rr} 
Variable & Levels & First Diff \\
\hline LSC & -3.145 & -7.790 \\
LCR & -2.612 & -4.928 \\
LUR & -1.192 & -6.027 \\
LEF & -3.245 & -5.656 \\
LNLF & -3.113 & -5.837
\end{tabular}

We continue with the cointegration analysis and present the result based on the trace of the stochastic matrix. This test supports the rejection of the null hypothesis $r=0$ and indicates that there is one cointegrating relationship $(r=1)$, table 3 presents the results of the cointegration test.

TABLE 3:A Cointegration Analysis of Serious Crime

\begin{tabular}{r|rrr} 
Null & Alternative & Trace Statistics & $95 \%$ \\
\hline$r=0$ & $r \geq 1$ & 78.1044 & 68.52 \\
$r \leq 1$ & $r \geq 2$ & 33.2222 & 47.52
\end{tabular}

The long run relationship among the variables can be summarized in the following estimated cointegrating relation in which the coefficient oflscris normalized to I (estimated standard errors appear in paranthesis):

Iscr $=-0.48 \mathrm{lcr}-043 \mathrm{lur}-0.561 \mathrm{f} 1 \mathrm{f}+4.07 \mathrm{led}-0.04$ trend

Our findings indicate that during the period under study the detection rate, the unemployment rate, the percentage of female in employment and the percentage of persons with tertiary education had significant imparts on serious crime. Specifically, our result indicate that the detection rate and crime are negatively related, as detection decreases the crime rate increases, providing support for the deterrence hypothesis. Furthermore, we found a positive relationship between unemployment and serious crime: high rates of unemployment indicate a lake of legal income opportunities, and this serve to reduce the opportunity cost of engaging in criminal activity. This has been also supported by Elis (1991), who examined annual crime rates in Jamaica for the period 1950-84, and found that high crime is associated with periods of high unemployment.

In contrast to the argument developed in the methodology section, we found a negative relationship between the employed female population and crime. Witt and Witte (2001), examining the relationship between female labour force participation and crime and crime rates in the United States,suggest that an increase in female labor force participation has a positive effect on the crime rate. Similar results were also reported by Entorf and Spengler (2000)it is possible that this result was obtained because an increased employed female population in United States which can be viewed as a labourmarket improvement may have raised family income especially in the case of female headed households and in addition improved women's structured position in society, a factor which imparts can be viewed as a negative effect on the serious crime rate. This was an expected result since as noted before an individual with this level of education would have access to legitimate earnings which increases the opportunity cost of committingcrimesuggest that an increase in female labour force participation has a positive effect on the crime rate.Sandra et al (2009) examined series crime in Trinidaland Tobago and found that rising female employment is associated with reduction in crime, a contradiction to many earlierstudies. However, the relationship between serious crime and percentage of female employment is negative, see table (4). (See appendix).

Finally, the percentage of persons with tertiary education had a negative effect on the serious crime rate. This was an expected result since as noted before an individual with this level of education would have access to legitimate earnings which increases the opportunity cost of committing a crime. 
Furthermore, we estimated the error correction coefficient to be at -0.710 (std. err. $=0.155$ ), which is statistically highly significant and suggests a quick speed of convergence to equilibrium.

\section{CONCLUSION}

In this study we empirical examined the effect of the clearance rate, the unemployment rate, the percentage of females in employment and the percentage of the labour force with tertiary education in serious crime in Nigeria. Our study concluded that all of these variables were very important in determining the serious crime rate. Particularly, and in line with the economic theory, we found that the clearance rate, unemployment rate and education variables have negative effect on serious crime, which is in line with the economic theory with regard to the clearance rate findings. Similarly, policy makers can use the results of this study to put systems in place to keep the unemployment rate low and to ensure that individuals have access to educational opportunities that encompass tertiary level education, and police clearance should be encouraged. We suggest that this may be associated with changes in family income and the woman's structural position in the society, but this association needs to be explored further. Even though this result does not agree with that found in other studies, a result such as this, which is particular to the Nigeria case, could be of significant benefit. It can serve as a starting point to other studies on criminality in the West African suburb. Future research should distinguish between property and violent crime (in which case the above factors may behave differently) and explore the role of social capital indicators (e.g religion and religiosity), alcohol consumption, demographic factors and media on criminal behavior.

\section{REFERENCES}

Beeker, G. (1968), 'Crime and Punishment: An Economic Approach', TheJournal of Political Economy, 79(2): 169-217.

Beeker, G. and Mulligan, C. (1997), 'The Endogenous Determination of Time Preference', The Quarterly Journal of Economics, 112(3): 726-58.

Cherry, T. and List, J. (2002), 'Aggregation Bias in the Economic Model of Crime', Economics Letters, 75(1): 8186.

Cohen, L. and Felson, M, (1979), 'Social Change and Crime Rate Trends: A Routine Activity Approach', American Sociological Review,44(4): 588-608.

De Albuquerque, K. and McElroy, J. L. (1999), 'Longitudinal Study of Serious Crime in the Caribbean', Caribbean Journal of Criminology and Social Psychology: 4(1/2): 32-70.

Entorf, H. and Spengler, H., 2000. 'Scioeconomic and Demographic Factors of Crime in Germany: Evidence From Panel Data of the German
States', International Review of Law and Economics, 20:75-106.

Herlich, I., 1973. 'Participation in Illegitimate Activities: A Theoretical and Empirical Investigation', The Journal of Political economy,81(3): 521-565.

Ellis H., 1991. 'Report on Research into the Causes of Crime and Violence in Jamaica: a Study of Prison Inmates'.Kingston: National Task Force on Crime and Violence.

Entrof, H. and Spengler, H., 2002.Crime in Europe: Causes and Consequences.New York: Springer.

Forst B, Bennett RR., 1999. 'Unemployment and crime: Implicationsfor the Caribbean', CaribbeanJournal of Criminology and Social Psychology, 3: 132-70.

Freeman, R., 1999.'The Economics of Crime.'In O. Ashenfelter and D. Card (eds), Handbook of Labour Economics, Elsevier Science, pp. 35293571.

Grogger, J., 1995. 'The Effect of Arrests on the Employment and Earnings of Young Men', QuarterlyJournal of Economics,110(1): 51-71.

Hale, C. and Sabbagh, D., 1991.'Testing the Relationship between Unemployment and Crime: A Methodological Comment and Empirical Analysis Using time Series Data from England and Wales'.Journal of Research in Crime and Delinquency, 28: 400-417.

Harriot, A., 2004. 'The Jamaica Crime Problem: Some policy considerations', in A. Harriott, F. Brathwaite, S. Wortley (eds). Crime and Criminal Justice in the Caribbean.Kingston: Arawak Publications.

Johansen, S., 1995.Likelihood-Based Inference Cointegrated Vector Autoregressive Models. Oxford: Oxford University Press.

Johansen, S., 1998. 'Statistical Analysis of Cointegration Vector', Journal of Economic Dynamics and Control,12: 231-54.

Lester D., 1999.'Suicide and homicide in Caribbean nations'.Perceptual and Motor Skills, 88(3): 1350.

Lochner, L., 2004. 'Education, work, and crime: a human capital approach'. International Economic Review, 45:811-43 
Merton R. K., 1983.The Economics of Crime and Law Enforcement.London: Macmillan.

Pyle, D. J. and Deahman D. F., 1994. 'Crime and the Business Cycle in Post-War Britain', British Journal of Criminology, 34(3): 339-357.

Raphael, S. and Winter-Ebmer, R., 2001.'Identifying the Effect of Unemployment on Crime'.Journal of Law and Economics,XLIV: 259-283.

Sandra Sookram, George Saridakis,MaukeshBasdeo,KerrySumesar-Rai. 2009. 'Serious Crime in Trinidad and Tobego' Salise Publications working papers

Saridakis, G., 2008. 'Violent Crime and Incentives in the Long Run" Evidence from England and Wales', Loughborough University Business School Occasional Papers Series, No. 2.

Saridakis, G., 2004. 'Violent Crime in the United States of America: A Time-Series Analysis Between 1960-2000', European Journal of Law and Economics, 18(2):203-221.

Shaw, C. and McKay, H., 1942.Juvenile Delinquency and UrbanAreas.Chicago: University of Chicago Press.
Smit, P. R., Mejier, R. F. and Groen, P-P.J., 2004. 'Detection Rates, An International Comparison', European Journal on Criminal Policy and Research,10(2-3): 225-253.

Sutherland, E. H., 1942. On Analyzing Crime.Chicago Press.

United Nations Office on Drugs and Crime and World Bank, 2007. Crime Violence and Development: Trends, Costs and Policy Options in the Caribbean. Report No. 37820. Washington D. C.The World Bank.

Williams, J. and Sickles, R. C., 2002.'An analysis of the crime as work model: Evidence from the Philadelphia Birth Cohort Study', Journal of Human Resources. 37(3): 479-509.

Witte, A., 1980. Estimating the Economic Model of Crime with individual Data', The Quarterly Journal of Economics, 94(1): 57-84.

Witt, R. and Witte, A., 2001.'Crime Causation: Economic Theories'.Encyclopedia of Crime and Justice. New York: Free Press. 


\section{APPENDIX}

TABLE 4:

Variable

LNSC

LNCR

LNUR

LNEF

LNLF

LNSC

1.0000

$-0.3822$

$-0.1493$

$-0.0824$

0.3012

LNCR

LNUR

LNEF

LNLF

1.0000

0.1008

$-0.0266$

$-0.1160$

1.0000
0.4210
0.1961

1.0000

$-0.0072$

1.0000

FIGUR 2
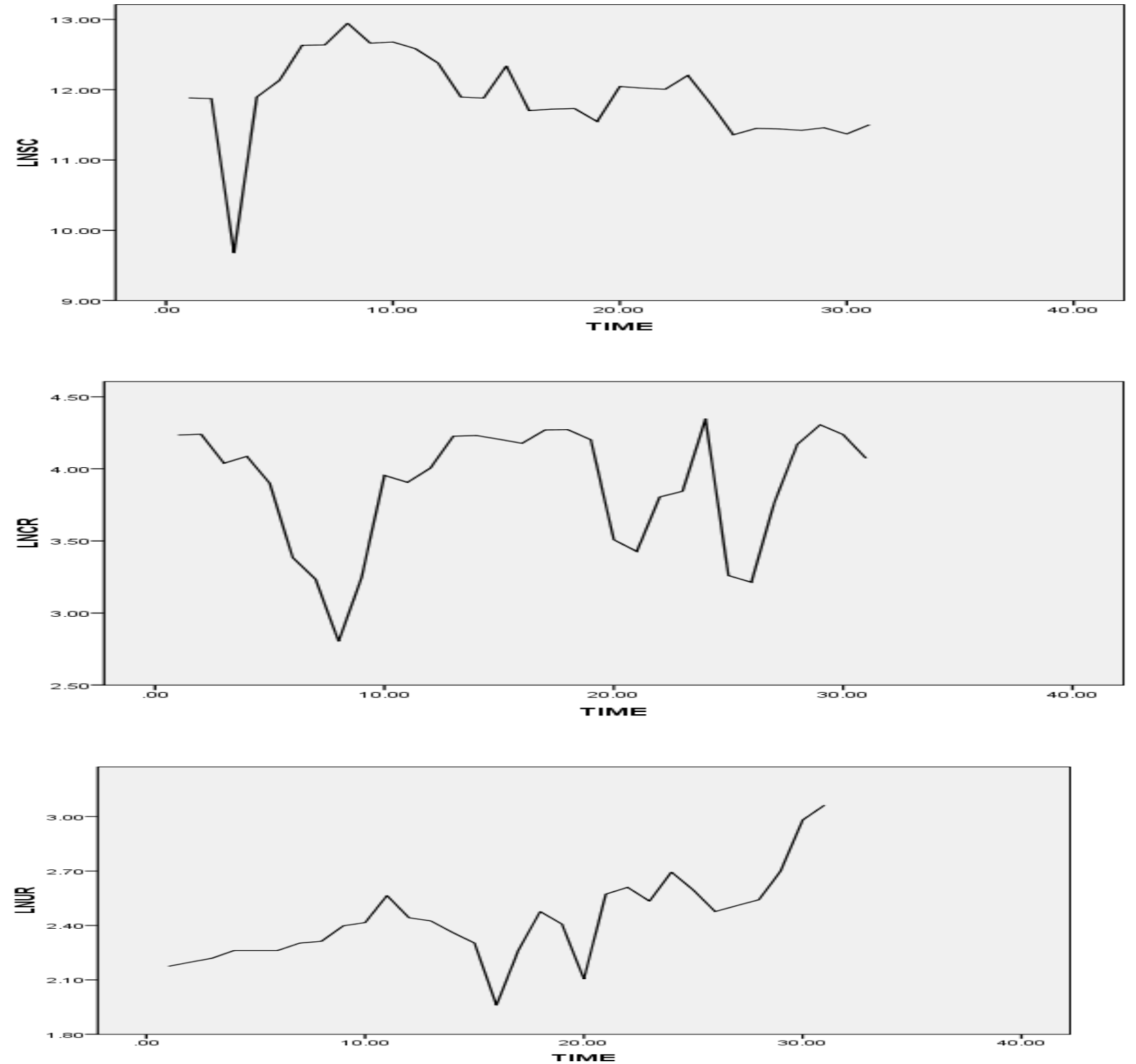

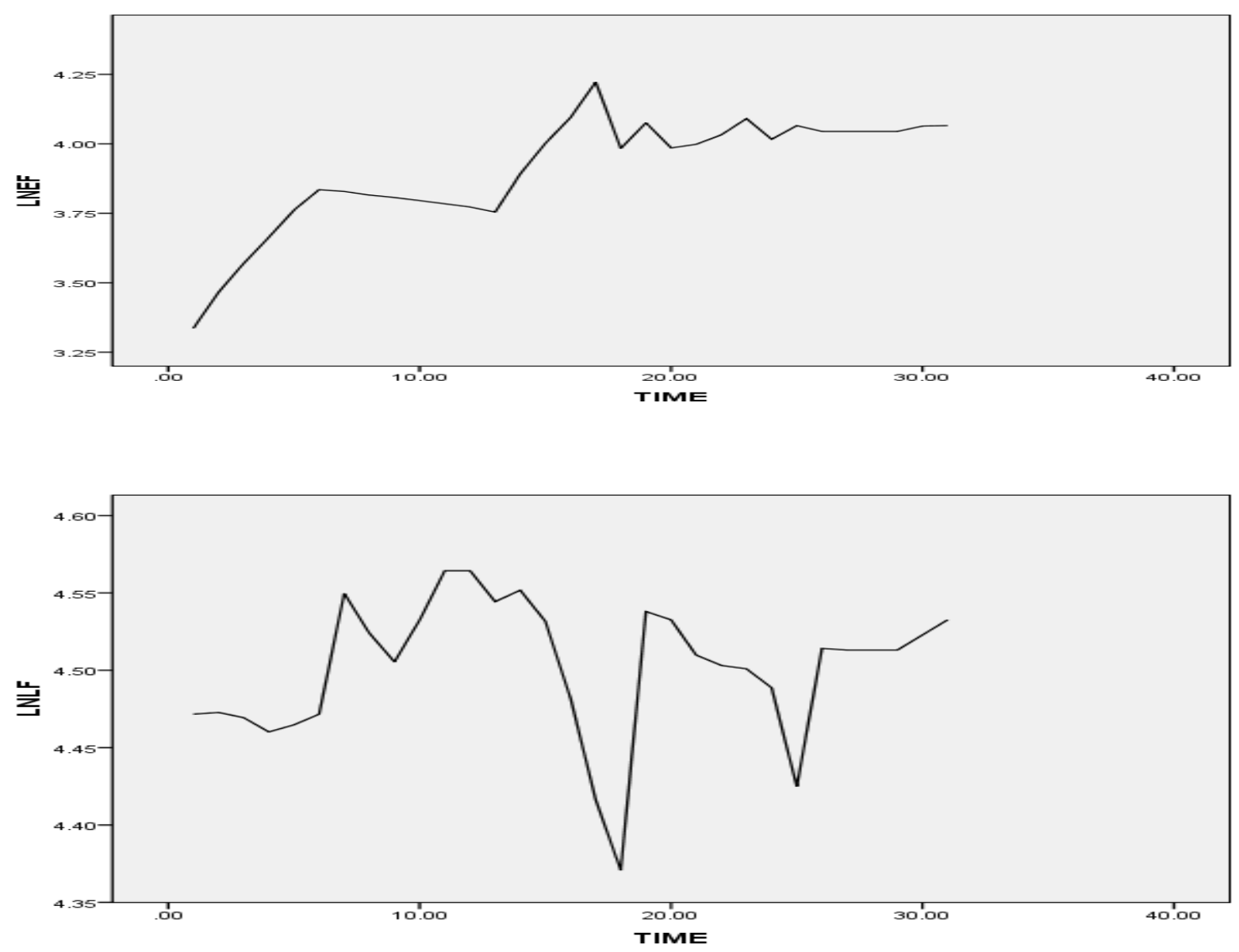